\title{
Modeling the Performance Limitations and Prospects of Perovskite/Si Tandem Solar Cells under Realistic Operating Conditions
}

\author{
Moritz H. Futscher ${ }^{(\circledR)}$ and Bruno Ehrler*(i) \\ Center for Nanophotonics, AMOLF, Science Park 104, 1098 XG Amsterdam, The Netherlands \\ Supporting Information
}

ABSTRACT: Perovskite/Si tandem solar cells have the potential to considerably out-perform conventional solar cells. Under standard test conditions, perovskite/Si tandem solar cells already outperform the $\mathrm{Si}$ single junction. Under realistic conditions, however, as we show, tandem solar cells made from current record cells are hardly more efficient than the $\mathrm{Si}$ cell alone. We model the performance of realistic perovskite/Si tandem solar cells under real-world climate conditions, by incorporating parasitic cell resistances, nonradiative recombination, and optical losses into the detailed-balance limit. We show quantitatively that when optimizing these parameters in the perovskite top cell, perovskite/Si tandem solar cells could reach efficiencies above $38 \%$ under realistic conditions, even while leaving the $\mathrm{Si}$ cell untouched. Despite the rapid efficiency increase of

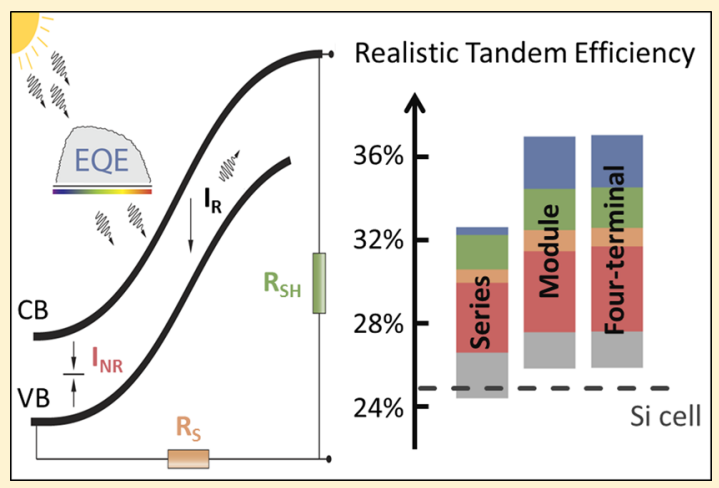
perovskite solar cells, our results emphasize the need for further material development, careful device design, and light management strategies, all necessary for highly efficient perovskite/ Si tandem solar cells.

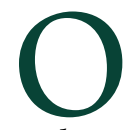
wing to the rapid increase in power conversion efficiency, metal-halide perovskite solar cells have become an auspicious candidate for cost-efficient tandem solar cells in combination with highly optimized $\mathrm{Si}$ solar cells. $^{1-7}$ In a tandem configuration, a perovskite cell is stacked on top of a Si cell to absorb the high-energy part of the solar spectrum, whereas the transmitted light is absorbed in the Si bottom cell. In doing so, the theoretical Shockley-Queisser limit, based on detailed balance, can be increased from $34 \%$ for a single-junction solar cell to $45 \%$ for a tandem solar cell from two subcells. ${ }^{8-11}$

Numerous perovskite/Si tandem solar cells have been reported in series-connected, four-terminal, and module tandem configurations, increasing the efficiency of the $\mathrm{Si}$ subcell alone. ${ }^{12-20}$ With a record efficiency of $26.4 \%,{ }^{21}$ perovskite/Si tandem solar cells almost match the current record efficiency of Si solar cells of $26.7 \%{ }^{22}$ Yet, even the best perovskite/Si tandem solar cells show only around half the efficiency of the detailed-balance efficiency limit. The efficiency is reduced due to parasitic absorption, nonradiative recombination $\left(J_{\mathrm{NR}}\right)$, undesirable series resistance $\left(R_{\mathrm{S}}\right)$ and shunt resistance $\left(R_{S H}\right)$, and optical losses. Furthermore, we recently showed that the power conversion efficiency of perovskite $/ \mathrm{Si}$ tandem solar cells is strongly affected by the considered tandem configuration, spectral variations, and temperature changes. ${ }^{23}$ Using empirical models, it was shown that the energy yield potential of monolithically integrated perovskite/Si tandem solar cells electrically connected in series are stronger effected by outdoor conditions than the four-terminal tandem configuration. $^{24,25}$ These considerations show that the interplay of real-world climate conditions and realistic solar cell parameters has to be considered for an approximation of the performance of these cells. Numerical optical simulations have shown that parasitic absorption losses in the perovskite top cell are one of the main limiting factors influencing the tandem efficiency and that perovskite/Si tandem solar cells require careful photon management for optimum device performance. $^{26-30}$ Numerical models can provide deep insight into the working principles of perovskite/Si solar cells, ${ }^{31}$ however, they require detailed knowledge about the specific device stack, rendering them unfavorable for fast characterization of the energy yield of tandem devices. Analytical models have been developed for perovskite solar cells and perovskite/Si tandem solar cells, showing the effect of device parameters such as nonradiative recombination, optical-thickness, and parasitic resistances and on the tandem efficiency. ${ }^{32,33}$ So far, however, a simple analytical model to understand the behavior of realistic

Received: July 7, 2017

Revised: August 17, 2017

Accepted: August 17, 2017 
perovskite/Si tandem solar cells under measured outdoor conditions is lacking.

Here we develop a simple, generic, and transferable model to simulate state-of-the-art perovskite solar cells by combining an optical model based on EQE measurements with an analytical electrical model based on current-voltage characteristics to predict the behavior of realistic perovskite/Si tandem solar cells under realistic conditions. This model provides clear guidelines to characterize and optimize perovskite/Si tandem solar cells by quantitatively including physical parameters such as nonradiative recombination, parasitic resistances, and optical losses into the detailed-balance model. Together with Si bottom cells, we simulate realistic perovskite/Si tandem solar cells under real-world climate conditions to predict the potential power yield. We show that the power conversion efficiency of perovskite/Si tandem solar cells is hardly better than that of the single-junction $\mathrm{Si}$ solar cell under realistic conditions, even when using the best available perovskite and $\mathrm{Si}$ solar cells to date (efficiency advantage $<1.5 \%$ absolute). We also find that the three tandem connection schemes (connected electrically in series, on the module level, or as independent four-terminal devices) show almost identical efficiency values $(<1.5 \%$ absolute difference). Only when reducing the parasitic absorption in the contacts do the tandem solar cells start to out-perform the single-junction $\mathrm{Si}$ cell by $1.8-3.3 \%$ absolute. Finally, we show how a reduction in nonradiative recombination, optimized series and shunt resistance, and a reduction in optical losses for the perovskite cell could boost the efficiency advantage of the tandem cell up to $14.0 \%$ absolute $(13.3 \%$ absolute for series tandem) compared to the single-junction cell. For these optimized cells, the connection scheme, as well as the climate conditions, become more important compared to nonoptimized cells.

Including realistic solar-cell parameters such as nonradiative recombination and parasitic resistances into the detailedbalance limit calculations allows for simulating realistic solar cell performance under real-world climate conditions (temperature, irradiance, and spectrum). In the detailed-balance limit, all recombination is radiative, all light above the bandgap is absorbed, and there are no optical losses (external quantum efficiency $(\mathrm{EQE})=1)$. Knowledge of the bandgap, temperature, incoming spectrum, and intensity then allows calculating the limiting efficiency of a solar cell. We extend the detailedbalance calculations to include nonradiative recombination, series resistance, shunt resistance, and the fact that not all light above the bandgap leads to photocurrent (optical losses, EQE < 1). The current-voltage characteristics is then given by

$$
\begin{aligned}
J= & J_{\mathrm{G}}-J_{\mathrm{R}}\left(e^{q\left(V+J R_{\mathrm{S}}\right) / k_{\mathrm{B}} T}-1\right)-J_{\mathrm{A}}\left(e^{3 q\left(V+J R_{\mathrm{S}}\right) / 2 k_{\mathrm{B}} T}-1\right) \\
& -J_{\mathrm{NR}, 1}\left(e^{q\left(V+J R_{\mathrm{S}}\right) / k_{\mathrm{B}} T}-1\right)-J_{\mathrm{NR}, 2}\left(e^{q\left(V+J R_{\mathrm{S}}\right) / 2 k_{\mathrm{B}} T}-1\right) \\
& -\frac{V+J R_{\mathrm{s}}}{R_{\mathrm{sh}}}
\end{aligned}
$$

where the first two terms correspond to the detailed-balance limit extended to include series resistance. Here $J$ is the total current density generated by the solar cell, $J_{\mathrm{G}}$ is the generated photocurrent density, $J_{\mathrm{R}}$ is the radiative recombination darksaturation current density, $q$ is the elementary charge, $V$ is the applied voltage, $k_{\mathrm{B}}$ is the Boltzmann constant, and $T$ is the temperature of the cell. The third term corresponds to the Auger recombination current density with its dark-saturation current density $J_{\mathrm{A}}$ and an ideality factor of $2 / 3$. The fourth and the fifth terms correspond to nonradiative recombination current densities with the corresponding dark-saturation current densities $J_{\mathrm{NR}, 1}$ and $J_{\mathrm{NR}, 2}$ and ideality factors of 1 and 2 , respectively, and the last term is due to shunt resistance (see Supporting Information (SI) S1 for a full description of the model). We note that in reality, the ideality factor that corresponds to a specific recombination channel is not a constant. Changes in temperature, irradiance, and spectrum can result in a variable ideality factor, e.g., by changes in the surfaceand bulk recombination, leading a different dependence on real-world climate conditions. While efficiencies up to $22.1 \%$ have been reported for very small cells, ${ }^{34}$ we model perovskite and $\mathrm{Si}$ solar cells based on current record efficiency devices $\geq 1$ $\mathrm{cm}^{2}$ to get more realistic values for the device resistances. ${ }^{35,36}$ The highest certified efficiency for those larger-area cells is $19.7 \%{ }^{22,34}$ We note that due to the large sheet resistance in the transparent contacts, smaller area perovskite devices usually show higher efficiencies than larger area devices. ${ }^{34}$ To simulate real-world climate conditions we use solar spectra, irradiance, and temperatures measured in Utrecht, The Netherlands ${ }^{37}$ and in Denver, Colorado, US $^{38}$ in 2015 at an interval of $30 \mathrm{~min}$ during daylight hours.

We fit our model to the current-voltage characteristics of record-efficiency perovskite and $\mathrm{Si}$ solar cells as shown in Figure 1. We include different mechanisms for nonradiative
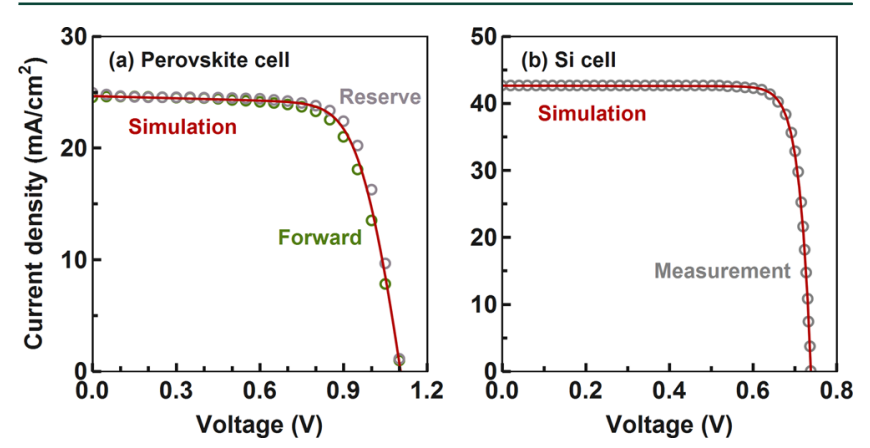

Figure 1. Modeled current-voltage characteristics of record efficiency (a) perovskite and (b) Si solar cells. The circles correspond to the measured data of the record efficiency (a) perovskite solar cell with a bandgap of $1.49 \mathrm{eV}^{35}$ and (b) Si solar cell. ${ }^{36}$ The fit parameters are summarized in Table 1.

recombination for the $\mathrm{Si}$ and perovskite subcells. To model the Si cell, we take Auger ${ }^{39}$ recombination $\left(J_{\mathrm{A}}\right)$ and a nonradiative diffusion current of minority carriers $\left(J_{\mathrm{NR}, 1}\right)$ into account. Since most of the perovskite layer is depleted, ${ }^{40-42}$ we assume the dominating recombination mechanism to be recombination from the space charge region $\left(J_{\mathrm{NR}, 2}\right)$. As a result, the dark current of the perovskite and the Si solar cell have different dependences on temperature, irradiance, and applied voltage (see SI S2 and S3 for details). The fitted parasitic resistances and dark current densities are summarized in Table 1. Optical losses such as reflection and parasitic absorption are included by fitting the EQE of the record $\mathrm{Si}$ and perovskite subcells. To account for the transparent contact of the perovskite top cell, we (optimistically) assume that it absorbs $10 \%$ of the incoming light prior to reaching the $\mathrm{Si}$ subcell, with additional absorption in the blue-UV region of the spectrum (see SI S4). ${ }^{20}$

Using these modeled perovskite and Si subcells, we calculate the efficiency for current-matched series, voltage-matched module, and unconstrained four-terminal tandem assembly strategies following previous work ${ }^{23}$ (see SI S4 for details). The 
Table 1. Fitted Solar Cell Parameters and Performance of Modeled Perovskite and Si Solar Cells ${ }^{a}$

$\begin{array}{lccccccc} & R_{\mathrm{S}}\left(\Omega \mathrm{cm}^{2}\right) & R_{\mathrm{SH}}\left(\Omega \mathrm{cm}^{2}\right) & J_{\mathrm{NR}}\left(\mathrm{pA} / \mathrm{cm}^{2}\right) & J_{\mathrm{SC}}\left(\mathrm{mA} / \mathrm{cm}^{2}\right) & V_{\mathrm{OC}}(\mathrm{V}) & \mathrm{FF}(\%) & \eta(\%) \\ \text { perovskite } & 3.10 & 1500 & 28.50 & 24.67 & 1.104 & 72.3 & 19.7 \\ \mathrm{Si} & 0.08 & 10000 & 0.01 & 42.65 & 0.738 & 84.9 & 26.7\end{array}$

${ }^{a}$ The perovskite solar cell is based on a perovskite mixture with a bandgap of $1.49 \mathrm{eV}$.

current record perovskite solar cell is based on a formamidinium lead iodide and methylammonium lead iodide mixture with a bandgap of $1.49 \mathrm{eV} .^{35}$ The ideal bandgap for a seriesconnected tandem solar cell with $\mathrm{Si}$ as a bottom cell is 1.74 $\mathrm{eV}^{43,44}$ we therefore set the optical thickness of the perovskite top cell to $82 \%$ in order to current-match the perovskite top cell and the Si bottom cell. An increase in the perovskite bandgap would lead to an optically thicker perovskite layer (see SI S5). For the module tandem, the ratio between the number of perovskite top cells and $\mathrm{Si}$ bottom cells was set to $1 / 1.39$ in order to voltage-match one perovskite top cell with $1.39 \mathrm{Si}$ bottom cells. We calculate the efficiencies of single-junction cells and different tandem configurations under standard test conditions (AM1.5G, $1 \mathrm{~kW} / \mathrm{m}^{2}, 25{ }^{\circ} \mathrm{C}$ ) and under real-world climate conditions averaged over an entire year (see Table 2 ). The average efficiency is weighted with the incoming intensity, to allow for a calculation of the integrated power conversion efficiency over the year.

Table 2. Intensity-Weighted Power Conversion Efficiency over an Entire Year for the Three Perovskite/Si Tandem Configurations and the Si Solar Cell under Standard Test Conditions (STC, AM1.5G, $1 \mathrm{~kW} / \mathrm{m}^{2}, 25^{\circ} \mathrm{C}$ ) and under Real-World Conditions at Two Locations with Distinctively Different Climate Conditions: Utrecht, The Netherlands $(\mathrm{NL})^{37}$ and Denver, Colorado $(\mathrm{CO})^{38 a}$

\begin{tabular}{c|cccc}
\multicolumn{1}{c}{$\begin{array}{c}\text { Si cell } \\
(\%)\end{array}$} & $\begin{array}{c}\text { Series } \\
(\%)\end{array}$ & $\begin{array}{c}\text { Module } \\
(\%)\end{array}$ & $\begin{array}{c}\text { Four-terminal } \\
(\%)\end{array}$ \\
\cline { 2 - 5 } & & & - & - \\
STC & 26.7 & 27.6 & 28.5 & 28.5 \\
NL & 24.6 & 24.3 & 25.5 & 25.6 \\
CO & 25.0 & 25.3 & 26.4 & 26.4
\end{tabular}

${ }^{a}$ The insets schematically illustrate the different tandem configurations, where the blue cells correspond to the perovskite top cells and the red to the Si bottom cells, with light incident from the top.

Rather surprisingly, combining record efficiency perovskite and Si solar cells in a tandem configuration would increase the efficiency only marginally compared to the single-junction $\mathrm{Si}$ solar cell alone. In fact, in the series tandem configuration, the efficiency is reduced by $0.3 \%$ absolute in The Netherlands, due to the stronger dependence on the incoming spectrum and irradiance. For this tandem configuration, the additional power generated in the perovskite top cell does not outweigh the losses introduced by placing the perovskite cell on top of the $\mathrm{Si}$ cell. We note that the difference between the different tandem configurations is less than $1.3 \%$ absolute, lower than expected from ideal cells. The losses compared to ideal cells are caused by shading part of the light from the Si cell in the perovskite solar cell contacts, but also from electrical losses as the electrical characteristics of the perovskite cell are not as highly optimized as those of the Si cell. These effects counteract some of the tandem specific losses due to spectrum and temperature changes, rendering the different tandem configurations similar in efficiency.

The efficiency of Si solar cells and perovskite/Si tandem solar cells as a function of solar irradiance, for ideal cells (Figure 2a)
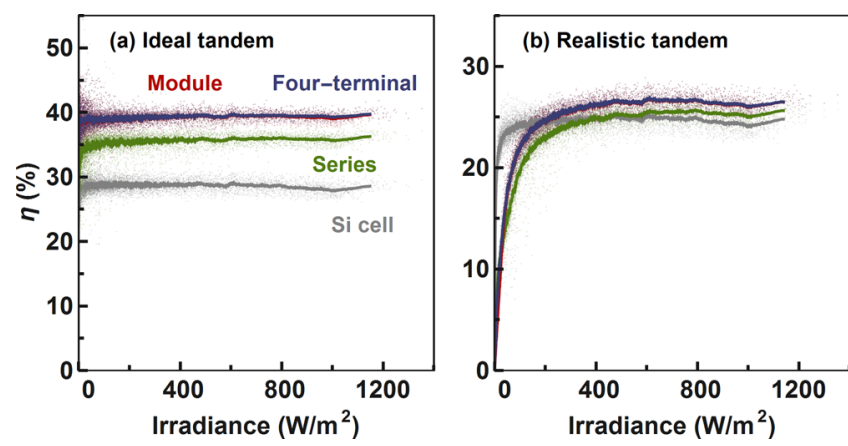

Figure 2. Efficiency of the three perovskite/Si tandem configurations and the perovskite solar cell under real-world conditions as a function of irradiance calculated using solar spectra and temperatures measured in Utrecht, The Netherlands ${ }^{37}$ for (a) ideal and $(b)$ record efficiency $S i$ and perovskite subcells. The solid line represents a moving average of the data.

and with realistic solar cell parameters such as $J_{\mathrm{NR}} R_{\mathrm{S}}$, and $R_{\mathrm{SH}}$ (Figure 2b) shows that the difference in efficiency between ideal and realistic cells is most prominent in the low-intensity region. Crucially, electrical losses are particularly harmful at low light intensity and are hence typically underestimated when the solar cells are evaluated under standard test conditions. The strong decrease in efficiency at low irradiance is due to unfavorable $R_{\mathrm{SH}}$, whereas the effects of $R_{\mathrm{S}}$ and $J_{\mathrm{NR}}$ are more prominent at high irradiance (see SI S6). In the following, we will examine how optimizing the parameters of the perovskite cell, such as parasitic absorption in the contacts, improving the electrical characteristics, and eliminating all optical losses, can lead to a massive increase in efficiency compared to both the single-junction Si cell, and the tandem cells made from state-ofthe-art subcells.

Assuming no parasitic absorption in the transparent contact of the perovskite cell leads to an increase in the efficiency of tandem solar cells between 1.8 and $3.3 \%$ absolute compared to the $\mathrm{Si}$ cell alone, depending on the considered tandem configuration and location. This increase stems from the increased current in the Si subcell. While this scenario might be unrealistic for typical transparent contacts, novel contacting schemes as well as nanowire contacts have been proposed to reduce the overall optical losses in the transparent contact. ${ }^{45-50}$ For simplicity, we assume no parasitic contact absorption in the perovskite top cell in the following discussion.

To understand the most practical ways to increase the efficiency of perovskite/Si tandem solar cells, we systematically change the parameters $J_{\mathrm{NR}}, R_{\mathrm{S}}$, and $R_{\mathrm{SH}}$ of the perovskite top cell in our model (Figure 3). For each calculation, the layer thickness of the perovskite top cell for the series tandem, and 

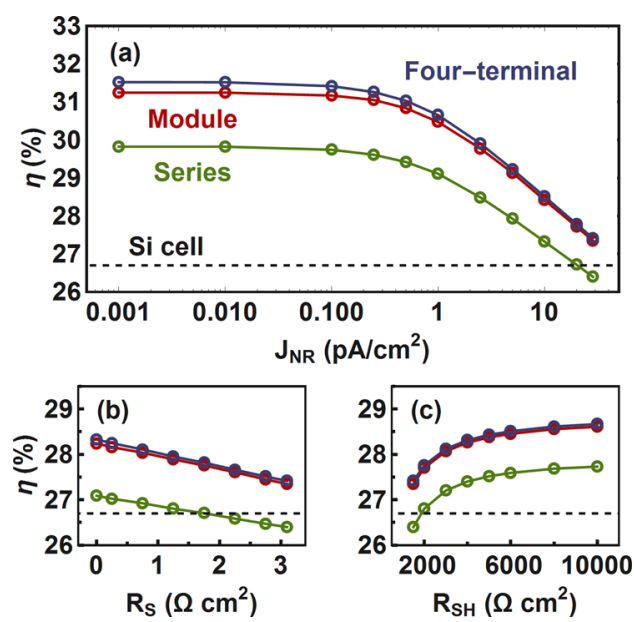

Figure 3. Effect of optimizing (a) nonradiative recombination $\left(J_{\mathrm{NR}}\right)$, (b) series resistance $\left(R_{\mathrm{S}}\right)$, and $(\mathrm{c})$ shunt resistance $\left(R_{\mathrm{SH}}\right)$, of the perovskite top cell on the intensity-weighted power conversion efficiency over a year for the three perovskite/Si tandem configuration calculated using solar spectra and temperatures measured in Utrecht, The Netherlands. ${ }^{37}$ The dashed line indicates the performance of the $\mathrm{Si}$ bottom cell at standard test conditions. The calculations assume no parasitic absorption in the perovskite cell contacts.

the ratio of Si to perovskite cells for the module tandem were optimized for maximum efficiency. Reducing the nonradiative recombination to $1 \mathrm{fA} / \mathrm{cm}^{2}$ of the perovskite subcell leads to a strong increase in power-conversion efficiency of up to $4.4 \%$ absolute. Optimizing parasitic resistances can further increase the efficiency by up to $1.3 \%$ absolute for $R_{\mathrm{S}}=0 \Omega \mathrm{cm}^{2}$ and up to $2.0 \%$ absolute for $R_{\mathrm{SH}}=10000 \Omega \mathrm{cm}^{2}$.

These changes in efficiency are different for the different tandem configurations. Due to the nonideal perovskite bandgap of $1.49 \mathrm{eV}$ for the record perovskite solar cell, ${ }^{35}$ the series tandem gains the least in efficiency by optimizing the perovskite subcell compared to the module and the four-terminal tandem. This is especially evident when optimizing $J_{\mathrm{NR}}$ and $R_{\mathrm{S}}$ of the perovskite top cell, where the module and the four-terminal tandem gain about $0.5 \%$ absolute more in efficiency than the series tandem. The reduction of nonradiative recombination is slightly more beneficial for the four-terminal tandem than for the module tandem since the module tandem is subject to voltage-matching. However, the module tandem benefits notably more from a decrease in $R_{\mathrm{S}}$ since a change in $R_{\mathrm{S}}$ strongly changes the slope of the current-voltage characteristic close to the open-circuit voltage.

So far we used the EQE of the record cells to account for optical losses due to reflection, parasitic absorption, and potential electrical losses. Assuming an ideal EQE of 1 for the perovskite subcell, the efficiency of the tandem cells can be further increased by about $0.4 \%$ for the series tandem and about $2.7 \%$ for the module and the four-terminal tandem. The series tandem is much less affected since the gain in current in the perovskite cell here is balanced by less light that it transmitted to the Si cell. For the module and four-terminal tandem cell, the perovskite cell was optically thick to start with, so the additional EQE gain is almost exclusively a current gain for the overall tandem cell.

After optimizing the perovskite subcell, there is a strong difference in efficiency between the series tandem, and the module and four-terminal tandem using a perovskite top cell with a nonideal bandgap of $1.49 \mathrm{eV}$, due to the need for a semitransparent perovskite layer. This difference in efficiency between the tandem configurations almost vanishes by using a perovskite cell with an ideal bandgap of $1.74 \mathrm{eV}$.

Taken together, optimizing the perovskite cells can lead to an efficiency advantage of a tandem cells up to $13.3 \%$ absolute for the series tandem and $14.0 \%$ absolute for the four-terminal tandem, even when leaving the Si cell untouched (Figure 4),

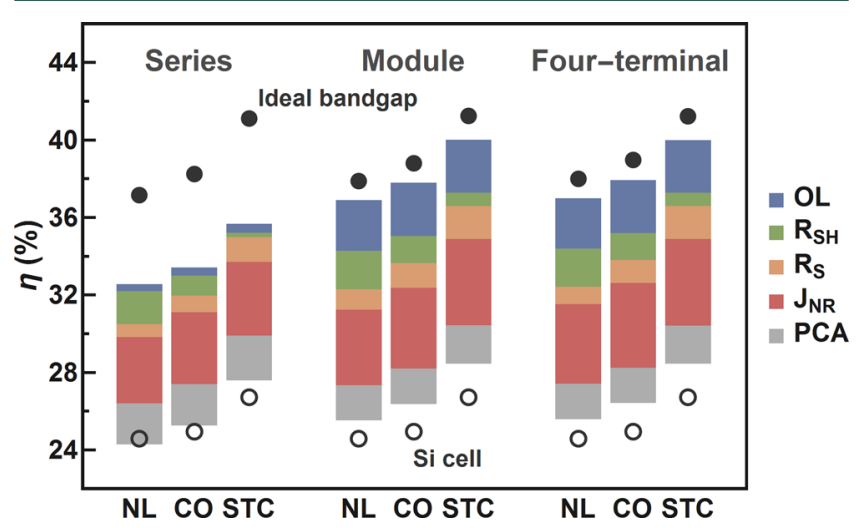

Figure 4. Effects of parasitic contact absorption losses (PCA), nonradiative recombination $\left(J_{\mathrm{NR}}\right)$, series resistance $\left(R_{\mathrm{S}}\right)$, shunt resistance $\left(R_{S H}\right)$, and optical losses $(\mathrm{OL})$ on the intensity-weighted power conversion efficiency over a year for the three perovskite/Si tandem configurations, calculated using standard test conditions (STC) and solar spectra and temperatures measured in Utrecht, The Netherlands $(\mathrm{NL})^{37}$ and in Denver, Colorado (CO). ${ }^{38}$ The empty circles indicate the efficiency of the Si bottom cell alone. The filled circles indicate the tandem efficiency when using an optimized perovskite top cell with an ideal bandgap of $1.74 \mathrm{eV}$.

reaching efficiencies up to $39.0 \%$. When optimized, the perovskite solar cell alone has an efficiency of $32.1 \%$ for a nonideal bandgap of $1.49 \mathrm{eV}$, and $28.4 \%$ for the ideal bandgap of $1.74 \mathrm{eV}$ under standard operating conditions (see Figure S17 in the SI for details).

How much of this efficiency improvement is realistic for perovskite solar cells? While this question is difficult to answer in such a dynamic research field, it is sensible to consider the progress of other solar cell materials. The high series resistance of the perovskite solar cell can be reduced close to zero by optimized electrical contacts, e.g., including metal fingers. The shunt resistance has successfully been optimized to very high values for most established thin-film and $\mathrm{Si}$ solar cells. ${ }^{51,52}$ Progress in optical performance, and in reducing the nonradiative recombination is more difficult to predict, but we note that $\mathrm{Si}$ and GaAs cells have been optimized optically to achieve $>95 \% \mathrm{EQE}$ over a very broad spectral range, ${ }^{36,53}$ and that the high radiative efficiency of some perovskite mixtures give reason to be optimiztic about reducing the nonradiative recombination. ${ }^{54}$

In addition to the record efficiency $\mathrm{Si}$ solar cell, we also simulate the performance of a tandem cell with a lowerefficiency $\mathrm{Si}$ cell that is commercially available, a Sunpower solar cell with an efficiency of $22.5 \%$. As above, we use the record perovskite solar cell with a bandgap of $1.49 \mathrm{eV}$ in a tandem configuration. The efficiency of the tandem cell is between 1.4 and $3.9 \%$ absolute higher compared to the Sunpower cell alone, less than expected for standard test conditions $(2.7-4.4 \%)$. Optimizing the perovskite top cell leads to an efficiency advantage of $16.1 \%(15.0 \%$ for the series 
tandem) absolute compared to the Sunpower cell alone, reaching efficiencies up to $37.0 \%$ (see SI S7 for details). These results show that a less efficient $\mathrm{Si}$ cell is somewhat easier to improve when using it in a tandem cell.

The efficiencies for the tandem configurations are different for the different locations. The Netherlands comprises a larger fraction of low-irradiance solar spectra throughout the year compared to Colorado. ${ }^{23}$ This difference in irradiance leads to a higher annual-averaged power conversion in Colorado than in The Netherlands (Figure 2). For the same reason, the reduction of $J_{\mathrm{NR}}$ and the improvement of $R_{\mathrm{S}}$ have a larger effect in Colorado, whereas the increase $R_{\mathrm{SH}}$ has a larger effect in The Netherlands.

We simulated realistic perovskite/Si tandem solar cells under real-world climate conditions. Our results show that, even with the current record efficiency perovskite and $\mathrm{Si}$ solar cells, a tandem cell would only marginally improve the efficiency of the Si cell alone under realistic operating conditions. For the series tandem cell, the efficiency of the tandem configuration can even be lower than the single-junction $\mathrm{Si}$ cell. When all parasitic absorption in the transparent contacts of the perovskite cell is reduced, the advantage in efficiency for the tandem cells amounts to $1.8-3.3 \%$ absolute compared to the Si singlejunction cell. This is far less than expected for ideal cells under ideal conditions, as the realistic cells are also more sensitive to the local climate conditions, in particular, the average irradiance. We show that further optimizing parasitic cell resistances, nonradiative recombination, and optical losses of the perovskite top cell can boost the efficiency advantage of the tandem cells by up to $12.9 \%$ absolute when using the nonideal bandgap of $1.49 \mathrm{eV}$, surpassing the single-junction ShockleyQueisser limit for all three tandem configurations under realistic operation conditions. This efficiency advantage can be further increased to $14.0 \%$ absolute when using the ideal perovskite bandgap of $1.74 \mathrm{eV}$. We show that reducing the nonradiative recombination, optimizing electrical nonidealities, and optical losses all have a large potential for efficiency gain. Optimizing the perovskite cell also leads to an increased efficiency difference between the series-connected tandem cells and the four-terminal and module tandem cells.

Perovskite cells have shown breathtaking development in efficiency in recent years. Yet, our results highlight the need for a concerted effort in material development (reducing nonradiative recombination and tuning the bandgap), device design (optimizing cell resistances), and light management strategies (reducing optical losses and developing transparent contacts) to further increase the efficiency of perovskite cells, and develop highly efficient perovskite/Si tandem solar cells.

\section{ASSOCIATED CONTENT}

\section{S Supporting Information}

The Supporting Information is available free of charge on the ACS Publications website at DOI: 10.1021/acsenergylett.7b00596.

Model for realistic solar cells under realistic conditions, various tandem configurations, the impact of nonradiative recombination and parasitic resistance on device efficiency, perovskite solar cell efficiency, and the experimental data used in the calculations (PDF)

Simulations of the tandem solar cell efficiency under realistic conditions are performed using Mathematica. The code can be downloaded free of charge at https://github.com/ HybridSolarCells/Tandem-Solar-Cell-Model.

\section{AUTHOR INFORMATION}

\section{Corresponding Author}

*E-mail: ehrler@amolf.nl; Group homepage. https://amolf.nl/ research-groups/hybrid-solar-cells; Twitter: @brunoehrler.

ORCID ब

Moritz H. Futscher: 0000-0001-8451-5009

Bruno Ehrler: 0000-0002-5307-3241

Notes

The authors declare no competing financial interest.

\section{ACKNOWLEDGMENTS}

The authors thank Wilfried van Sark and Atse Louwen from the Utrecht Photovoltaic Outdoor Test facility (UPOT), and the NREL Solar Radiation Research Laboratory for providing spectral irradiance and temperature data, Henk-Jan Boluijt for the graphical illustration of our model, and Erik Garnett for carefully reading and commenting on the manuscript. This work is part of the research program of The Netherlands Organization for Scientific Research (NWO).

\section{REFERENCES}

(1) Kojima, A.; Teshima, K.; Shirai, Y.; Miyasaka, T. Organometal Halide Perovskites as Visible-Light Sensitizers for Photovoltaic Cells. J. Am. Chem. Soc. 2009, 131, 6050-6051.

(2) Polman, A.; Knight, M.; Garnett, E. C.; Ehrler, B.; Sinke, W. C. Photovoltaic Materials - Present Efficiencies and Future Challenges. Science 2016, 352, 307.

(3) Correa-Baena, J.-P.; Abate, A.; Saliba, M.; Tress, W.; Jesper Jacobsson, T.; Grätzel, M.; Hagfeldt, A. The Rapid Evolution of Highly Efficient Perovskite Solar Cells. Energy Environ. Sci. 2017, 10, 710727.

(4) Chen, B.; Zheng, X.; Bai, Y.; Padture, N. P.; Huang, J. Progress in Tandem Solar Cells Based on Hybrid Organic-Inorganic Perovskites. Adv. Energy Mater. 2017, 7, 1602400.

(5) Green, M. A.; Ho-Baillie, A. Perovskite Solar Cells: The Birth of a New Era in Photovoltaics. ACS Energy Lett. 2017, 2, 822-830.

(6) White, T. P.; Lal, N. N.; Catchpole, K. R. Tandem Solar Cells Based on High - Efficiency c - Si Bottom Cells: Top Cell Requirements for $>30 \%$ Efficiency. IEEE J. PHOTOVOLTAICS 2014, 4, 208-214.

(7) Graydon, O. View from $\cdots$ PSCO 2016: The Race for Tandems. Nat. Photonics 2016, 10, 754-755.

(8) Shockley, W.; Queisser, H. J. Detailed Balance Limit of Efficiency of p-n Junction Solar Cells. J. Appl. Phys. 1961, 32, 510-519.

(9) Vos, A. D. Detailed Balance Limit of the Efficiency of Tandem Solar Cells. J. Phys. D: Appl. Phys. 1980, 13, 839-849.

(10) Henry, C. H. Limiting Efficiencies of Ideal Single and Multiple Energy Gap Terrestrial Solar Cells. J. Appl. Phys. 1980, 51, 4494-4500.

(11) Martí, A.; Araújo, G. L. Limiting Efficiencies for Photovoltaic Energy Conversion in Multigap Systems. Sol. Energy Mater. Sol. Cells 1996, 43, 203-222.

(12) Bailie, C. D.; Christoforo, M. G.; Mailoa, J. P.; Bowring, A. R.; Unger, E. L.; Nguyen, W. H.; Burschka, J.; Pellet, N.; Lee, J. Z.; Grätzel, M.; et al. Semi-Transparent Perovskite Solar Cells for Tandems with Silicon and CIGS. Energy Environ. Sci. 2015, 8, 956963.

(13) Löper, P.; Moon, S.-J.; Martín de Nicolas, S.; Niesen, B.; Ledinsky, M.; Nicolay, S.; Bailat, J.; Yum, J.-H.; De Wolf, S.; Ballif, C. Organic-Inorganic Halide Perovskite/Crystalline Silicon Four-Terminal Tandem Solar Cells. Phys. Chem. Chem. Phys. 2015, 17, 16191629.

(14) Werner, J.; Weng, C. H.; Walter, A.; Fesquet, L.; Seif, J. P.; De Wolf, S.; Niesen, B.; Ballif, C. Efficient Monolithic Perovskite/Silicon 
Tandem Solar Cell with Cell Area $>1 \mathrm{~cm} 2$. J. Phys. Chem. Lett. 2016, $7,161-166$.

(15) Albrecht, S.; Saliba, M.; Correa Baena, J. P.; Lang, F.; Kegelmann, L.; Mews, M.; Steier, L.; Abate, A.; Rappich, J.; Korte, L.; et al. Monolithic Perovskite/Silicon-Heterojunction Tandem Solar Cells Processed at Low Temperature. Energy Environ. Sci. 2016, 9, 8188.

(16) Duong, T.; Lal, N.; Grant, D.; Jacobs, D.; Zheng, P.; Rahman, S.; Shen, H.; Stocks, M.; Blakers, A.; Weber, K.; et al. Semitransparent Perovskite Solar Cell With Sputtered Front and Rear Electrodes for a Four-Terminal Tandem. IEEE J. Photovoltaics 2016, 6, 679-687.

(17) Werner, J.; Barraud, L.; Walter, A.; Bräuninger, M.; Sahli, F.; Sacchetto, D.; Tétreault, N.; Paviet-Salomon, B.; Moon, S.-J.; Allebé, C.; et al. Efficient Near-Infrared-Transparent Perovskite Solar Cells Enabling Direct Comparison of 4-Terminal and Monolithic Perovskite/Silicon Tandem Cells. ACS Energy Lett. 2016, 1, 474-480.

(18) Chen, B.; Bai, Y.; Yu, Z.; Li, T.; Zheng, X.; Dong, Q.; Shen, L.; Boccard, M.; Gruverman, A.; Holman, Z.; et al. Efficient Semitransparent Perovskite Solar Cells for 23.0\%-Efficiency Perovskite/ Silicon Four-Terminal Tandem Cells. Adv. Energy Mater. 2016, 6, 1601128.

(19) Jaysankar, M.; Qiu, W.; van Eerden, M.; Aernouts, T.; Gehlhaar, R.; Debucquoy, M.; Paetzold, U. W.; Poortmans, J. Four-Terminal Perovskite/Silicon Multijunction Solar Modules. Adv. Energy Mater. 2017, 7, 1602807.

(20) Bush, K. A.; Palmstrom, A. F.; Yu, Z. J.; Boccard, M.; Cheacharoen, R.; Mailoa, J. P.; McMeekin, D. P.; Hoye, R. L. Z.; Bailie, C. D.; Leijtens, T.; et al. 23.6\%-Efficient Monolithic Perovskite/Silicon Tandem Solar Cells with Improved Stability. Nat. Energy 2017, 2, 17009 .

(21) Duong, T.; Wu, Y.; Shen, H.; Peng, J.; Fu, X.; Jacobs, D.; Wang, E.-C.; Kho, T. C.; Fong, K. C.; Stocks, M.; et al. Rubidium Multication Perovskite with Optimized Bandgap for Perovskite-Silicon Tandem with over 26\% Efficiency. Adv. Energy Mater. 2017, 7, 1700228.

(22) Green, M. A.; Hishikawa, Y.; Warta, W.; Dunlop, E. D.; Levi, D. H.; Hohl-Ebinger, J.; Ho-Baillie, A. W. H. Solar Cell Efficiency Tables (version 50). Prog. Photovoltaics 2017, 25, 668-676.

(23) Futscher, M. H.; Ehrler, B. Efficiency Limit of Perovskite/Si Tandem Solar Cells. ACS Energy Lett. 2016, 1, 863-868.

(24) Duck, B. C.; Dunbar, R. B.; Lee, O.; Anderson, K. F.; Jones, T. W.; Wilson, G. J.; Fell, C. J. Energy Yield Potential of PerovskiteSilicon Tandem Devices. In 2016 IEEE 43rd Photovoltaic Specialists Conference (PVSC); IEEE: New York, 2016; pp 1624-1629.

(25) Paetzold, U. W.; Gehlhaar, R.; Tait, J.; Qiu, W.; Bastos, J.; Debucquoy, M.; Jaysankar, M.; Aernouts, T.; Poortmans, J. Optical Loss Analyses and Energy Yield Modelling of Perovskite/Silicon Multijunction Solar Cells. In Light, Energy and the Environment; OSA: Washington, D.C., 2016; p SoW2C.4.

(26) Grant, D.; Weber, K.; Stocks, M.; White, T. P. Optical Optimization of Perovskite-Silicon Reflective Tandem Solar Cell. In Light, Energy and the Environement 2015; OSA: Washington, D.C., 2015; p PTh3B.3.

(27) Grant, D. T.; Catchpole, K. R.; Weber, K. J.; White, T. P. Design Guidelines for Perovskite/Silicon 2-Terminal Tandem Solar Cells: an Optical Study. Opt. Express 2016, 24, A1454.

(28) Jäger, K.; Korte, L.; Rech, B.; Albrecht, S. Numerical Optical Optimization of Monolithic Planar Perovskite-Silicon Tandem Solar Cells with Regular and Inverted Device Architectures. Opt. Express 2017, 25, A473.

(29) Santbergen, R.; Mishima, R.; Meguro, T.; Hino, M.; Uzu, H.; Blanker, J.; Yamamoto, K.; Zeman, M. Minimizing Optical Losses in Monolithic Perovskite/c-Si Tandem Solar Cells with a Flat Top Cell. Opt. Express 2016, 24, A1288.

(30) Martins, A.; Borges, B.-H. V.; Li, J.; Krauss, T. F.; Martins, E. R. Photonic Intermediate Structures for Perovskite/c-Silicon Four Terminal Tandem Solar Cells. IEEE J. Photovoltaics 2017, 1-7.

(31) Zhou, Y.; Gray-Weale, A. A Numerical Model for Charge Transport and Energy Convention of Perovskite Solar Cells. Phys. Chem. Chem. Phys. 2016, 18, 4476-4486.
(32) Islam, M.; Wahid, S.; Alam, M. K. Physics-Based Modeling and Performance Analysis of Dual Junction Perovskite/Silicon Tandem Solar Cells. Phys. Status Solidi A 2017, 214, 1600306.

(33) Sun, X.; Asadpour, R.; Nie, W.; Mohite, A. D.; Alam, M. A. A Physics-Based Analytical Model for Perovskite Solar Cells. IEEE J. Photovoltaics 2015, 5, 1389-1394.

(34) Yang, W. S.; Park, B.-W.; Jung, E. H.; Jeon, N. J.; Kim, Y. C.; Lee, D. U.; Shin, S. S.; Seo, J.; Kim, E. K.; Noh, J. H.; et al. Iodide Management in Formamidinium-Lead-Halide-based Perovskite Layers for Efficient Solar Cells. Science 2017, 356, 1376-1379.

(35) Yang, W. S.; Noh, J. H.; Jeon, N. J.; Kim, Y. C.; Ryu, S.; Seo, J.; Seok, S. Il. High-Performance Photovoltaic Perovskite Layers Fabricated through Intramolecular Exchange. Science 2015, 348, 1234-1237.

(36) Yoshikawa, K.; Kawasaki, H.; Yoshida, W.; Irie, T.; Konishi, K.; Nakano, K.; Uto, T.; Adachi, D.; Kanematsu, M.; Uzu, H.; et al. Silicon Heterojunction Solar Cell with Interdigitated Back Contacts for a Photoconversion Efficiency over 26\%. Nat. Energy 2017, 2, 17032.

(37) van Sark, W. G. J. H. M.; Louwen, A.; de Waal, A. C.; Elsinga, B.; Schropp, R. E. I. UPOT: The Utrecht Photovoltaic Outdoor Test Facility. In 27th European Photovoltaic Solar Energy Conference and Exhibition; WIP: Munich, Germany, 2012; pp 3247-3249.

(38) Stoffel, T.; Andreas, A. Baseline Measurement System (BMS); NREL Solar Radiation Research Laboratory (SRRL): Golden, Colorado, 1981.

(39) Tiedje, T.; Yablonovitch, E.; Cody, G. D.; Brooks, B. G. Limiting Efficiency of Silicon Solar Cells. IEEE Trans. Electron Devices 1984, 31, 711-716.

(40) Laban, W. A.; Etgar, L. Depleted Hole Conductor-Free Lead Halide Iodide Heterojunction Solar Cells. Energy Environ. Sci. 2013, 6, 3249.

(41) Guerrero, A.; Juarez-Perez, E. J.; Bisquert, J.; Mora-Sero, I.; Garcia-Belmonte, G. Electrical Field Profile and Doping in Planar Lead Halide Perovskite Solar Cells. Appl. Phys. Lett. 2014, 105, 133902.

(42) Aharon, S.; Gamliel, S.; El Cohen, B.; Etgar, L. Depletion Region Effect of Highly Efficient Hole Conductor Free CH3NH3PbI3 Perovskite Solar Cells. Phys. Chem. Chem. Phys. 2014, 16, 1051210518.

(43) McMeekin, D. P.; Sadoughi, G.; Rehman, W.; Eperon, G. E.; Saliba, M.; Horantner, M. T.; Haghighirad, A.; Sakai, N.; Korte, L.; Rech, B.; et al. A Mixed-Cation Lead Mixed-Halide Perovskite Absorber for Tandem Solar Cells. Science 2016, 351, 151-155.

(44) Albrecht, S.; Saliba, M.; Jäger, K.; Korte, L.; Hagfeldt, A.; Grätzel, M.; Rech, B. Towards Optical Optimization of Planar Monolithic Perovskite/Silicon-Heterojunction Tandem Solar Cells. J. Opt. 2016, 18, 064012.

(45) Bryant, D.; Greenwood, P.; Troughton, J.; Wijdekop, M.; Carnie, M.; Davies, M.; Wojciechowski, K.; Snaith, H. J.; Watson, T.; Worsley, D. A Transparent Conductive Adhesive Laminate Electrode for High-Efficiency Organic-Inorganic Lead Halide Perovskite Solar Cells. Adv. Mater. 2014, 26, 7499-7504.

(46) Sciacca, B.; van de Groep, J.; Polman, A.; Garnett, E. C. Solution-Grown Silver Nanowire Ordered Arrays as Transparent Electrodes. Adv. Mater. 2016, 28, 905-909.

(47) Ago, H.; Petritsch, K.; Shaffer, M. S. P.; Windle, A. H.; Friend, R. H. Composites of Carbon Nanotubes and Conjugated Polymers for Photovoltaic Devices. Adv. Mater. 1999, 11, 1281-1285.

(48) You, P.; Liu, Z.; Tai, Q.; Liu, S.; Yan, F. Efficient Semitransparent Perovskite Solar Cells with Graphene Electrodes. Adv. Mater. 2015, 27, 3632-3638.

(49) Lee, J. M.; Futscher, M. H.; Pazos-Outon, L. M.; Ehrler, B. Highly Transparent Singlet Fission Solar Cell with Multi-Stacked Thin Metal Contacts for Tandem Applications. Prog. Photovoltaics 2017, DOI: $10.1002 /$ pip.2919.

(50) Adhyaksa, G. W. P.; Johlin, E.; Garnett, E. C. Nanoscale Back Contact Perovskite Solar Cell Design for Improved Tandem Efficiency. Nano Lett. 2017, DOI: 10.1021/acs.nanolett.7b01092.

(51) Feurer, T.; Reinhard, P.; Avancini, E.; Bissig, B.; Löckinger, J.; Fuchs, P.; Carron, R.; Weiss, T. P.; Perrenoud, J.; Stutterheim, S.; et al. 
Progress in Thin Film CIGS Photovoltaics - Research and Development, Manufacturing, and Applications. Prog. Photovoltaics 2017, 25, 645-667.

(52) Sites, J.; Munshi, A.; Kephart, J.; Swanson, D.; Sampath, W. S. Progress and Challenges with CdTe Cell Efficiency. In Conference Record of the IEEE Photovoltaic Specialists Conference; IEEE: New York, 2016; Vol. 2016-Novem, pp 3632-3635.

(53) Kayes, B. M.; Nie, H.; Twist, R.; Spruytte, S. G.; Reinhardt, F.; Kizilyalli, I. C.; Higashi, G. S. 27.6\% Conversion Efficiency, a New Record for Single-Junction Solar Sells under 1 Sun Illumination. 2011 37th IEEE Photovoltaic Specialists Conference; IEEE: New York, 2011; pp 4-8.

(54) Deschler, F.; Price, M.; Pathak, S.; Klintberg, L. E.; Jarausch, D.D. D.; Higler, R.; Hüttner, S.; Leijtens, T.; Stranks, S. D.; Snaith, H. J.; et al. High Photoluminescence Efficiency and Optically-Pumped Lasing in Solution-Processed Mixed Halide Perovskite Semiconductors. J. Phys. Chem. Lett. 2014, 5, 1421-1426.

(55) Höranter, M. T.; Snaith, H. Predicting and Optimising the Energy Yield of Perovskite-on-Silicon Tandem Solar Cells under Real World Conditions. Energy Environ. Sci. 2017, DOI: 10.1039/ C7EE01232B.

\section{NOTE ADDED IN PROOF}

Corroborating evidence has been published during the review of this paper. 